\title{
SCHETSEN UIT SURINAME
}

DOOR

G. J. STAAL

\section{Levensavond}

De vloed stond door in de Boven-Commewijne.

In breede golven was het vloedwater aangedrongen uit den Atlantischen Oceaan in de monding der Suriname, langs Braamspunt, over het heete zeestrand, de zandplaat over, duwend en stuwend door het ijzeren netwerk van het geleidelicht en het paalwerk van plantagesteigers, Zuidwaarts naar de stad, Oostwaarts de Commewijne binnen, zijwaarts wijkend in open trenzen ${ }^{1}$ ) en kreken, langs voorpolders ${ }^{2}$ ) en gesloten sluizen opgedreven en in de bocht bij Constantia en Alliance aangezwollen door het tij, dat binnenliep uit Warappe en Matappica; rond den land-wig van Sommelsdijk vloeide het uit over Commetewane, Cottica en Boven-Commewijne.

Langs den rivieroever was druk-trillend geritsel in het heester-gewas van den slijkbodem van het voorland. Ruischend viel het water uit over den zelfkant van slib; het glipte over de modderlagen en dekte weldadig de weeke, gladde ruggen, die de eb had blootgelegd en de hevige zon bestookt.

Tusschen de moko-moko ${ }^{3}$ ) versplinterden vloedgolfjes in duizenden spartelende sprankjes, waarin de stralen van de zinkende zon sprinkelend braken. Onder den schokken-

1) trens = sloot. ${ }^{2}$ ) polder $=$ dam, dijk.

3) Moko moko $=$ Aronskelk met recht opstaanden stengel. 
den drang van het aanrukkend water zwenkten de lenige stengels, zoo niet een feller watervlaag al wat oprees uit den lagen oever neerboog met krachtigen zwaai.

Het was alom bewegen: grassen en pluimen en stelen stieten elkander aan; de paarsche bloemen van de brantimaka bengelden onrustig mede en waar het rijzende water het laag gebladerte raakte, huppelde het lenige groen, stroomopwaarts gericht.

Hooger, nader aan de damkruinen, deelden de slib-gewassen hunne schokken mede aan de stijvere oeverplanten; veel-kleurige bloemen, schitterende klokken van convulvulaceeën, schommelden er, zwakjes gewiegd, aan grillige slierten, die de struiken droegen.

Maar vast van stand bleef, door sterker stam gestut, het vlammend-roode sieraad van den bosch-cacao.

Het water steeg. De aanlegsteiger van den grond „De Goede Verwachting", - twee mambarklak-balken, ruwbekapt, uitgelegd van den voorpolder in het drassige voorland, - zonk dieper weg; het water klom op tegen de schuine balken naar de hoogte-lijn, de scheidingslijn der verkleuring van het hout waar elken dag twee malen het vloedpeil reikte.

Hurkend gedoken zat de oude baas Marius op de lage bank, zijn eigen rustiek werkstuk uit lang voorbijen tijd, onder den donkergroenen, machtigen bladerenkoepel van den statigen manja-boom, die zijn forsche schaduwvlek, nu verflauwend in het late middaguur, breed uitspreidde over het open voorerf.

Van de vijf ketting ${ }^{1}$ ) frontbreedte van den grond, aan de rivierzijde, was een paar ketting ontboscht en schoon gewied, aan den linkerkant waar een smalle rits ${ }^{2}$ ) naar achteren liep, in de richting van de Cottica. Op dit hooger land was het woonerf aangelegd; daar stond de manjaboom en, dieper in, het houten huis, door Marius zelven gebouwd toen hij zich met zijne jonge vrouw vestigde op het perceel, brokstuk van de verlaten plantage Breukelerwaard.

Marius was moe. Hij had hout gekapt van een koffie-

$\left.{ }^{1}\right)$ Ketting $=20,72047$ Meter. ${ }^{2}$ ) rits $=$ rugvormige bodemverheffing. 
mama ${ }^{1}$ ), die uit het cacao-veld in de loostrens gevallen was. Door de verwaarloozing van de bedelving had het water ten langen leste den grond om de wortels uitgespoeld; de schaduwboom was verzakt, gevallen, met den kruin in de trens, waar het vastgehouden slib een drempel vormde en den waterloop stoorde. Zij wisten het wel, Marius en zijn schoonzoon, maar zij lieten den boom langen tijd liggen.

Totdat, in den vroegen ochtend, Marius zich verzette tegen zichzelven, den bijl kneep in de pezige verweerde handen en begon te ruimen, met forsche halen, als wilde hij, over den tijd heen, de oude kracht laten herleven, waarmede hij eens geveld en gespleten had, dáár, op zijn grond en in de houtgronden aan de Para.

Maar de oude kracht herleefde niet: matter viel de bijl in den stam en de taaie splinters bleven steken in de kapgeulen. Nu zat hij, ingezonken, met pijnlijken rug en moebelaste schouders; de hand, die het héél korte, doorrookte steenen pijpje in den mondhoek drukte, beefde. Loom zoog hij den rook in van de grove, walmende tabak; loom hing het breede bovenlijf over de puntige knieën; in den inkijk van het open baadje puilden scherp de ribben, waar het vleesch was weggeslonken, en vlekte ontkleurd de verslapte, verdofte huid, die eenmaal vlekkeloos-zwart en glanzend het gezonde vleesch strak had omspannen. Nog stonden de groote, platte voeten stevig op den grond, als waren zij er aangeklonken met de breede, wijdgestrekte teenen: de sterke steun-voeten,gesterkt door het loopen op glibberige paden en het vastgrijpen in drassigen tuingrond.

Krachtig nog droeg de stoere nek het massieve negerhoofd. Wel was het stug-gekroesde haar gelig-wit verschoten, maar het dekte den schedel nog vol als met een dikke kap van stijf gevlochten touw-krullen; wel was het oogenwit niet smetteloos meer - bloedrood dooraderd was het groezelig geworden - maar in de groote donkere pupillen lichtte toch een levend licht, dat het goede, vriendelijke gelaat verhelderde. En als de lippen opengingen, dan schitterde het gaaf ivoor-blank van ongeschonden tandenrijen.

1) Koffie-mama = schaduwboom voor koffie en cacao. 


\section{II}

Met den vloed vloeiden oude tijden weer.

Marius keek naar zijne woning en zag er het verleden als eene omlijsting.

Hij was geboren op de plantage „De Overvloed” — in het Neger-Engelsch Kwassi-djompo genoemd als herinnering aan den sprong van den slaaf Kwassi in de Matappica na zijn aanslag op den bastiaan tijdens den aanleg van den staat $^{1}$ ). Hij was geboren in de schaduw van katoenboomen, in de avond-schemering van den slaventijd. Zijn vader Apenta was er timmerbaas en bootenmaker; hij had zijn zoon, die toen nog Mentor heette, - zijn naam Marius kreeg hij eerst later, bij den doop door den zendeling der Broedergemeente, - als helper opgeleid in zijn vak.

Marius had de ellende van den slaventijd niet zelf in haar wreedste gedaante gekend. Mildere wetten en zeden hadden het uiterlijk wee al veel verzacht toen hij als slaven-kind ter wereld kwam, eigendom en zelf slaaf van den landheer Obdam.

Veel echter had hij ervan gehoord, 's avonds na den arbeid, als slaven-groepen bijeenhokten voor de woningloodsen, de rijen van armelijke, kale kamertjes achter op het emplacement. Hij hoorde er van eigengerechtigde, barre geeselingen om nietige verzuimen; van het pijnigen en ophangen van slaven, opgevangen wegloopers; van den Spaanschen bok hoorde hij, het marteltuig in fort Zeelandia; en ook van den vuurdood van Kodjo, die met zijn trawanten in 1832 de stad, Paramaribo, in brand gestoken had; en van die wreede vrouw hoorde hij, wier naam berucht bleef in het gansche land, die in haar tentboot huiswaarts geroeid, het huilende kind van een van hare slavinnen wegrukte van de moeder, onder water hield en dood teruggaf met de woorden: nu zal het wel stil blijven.

Uit het eigen beleven in den tijd van het opklaren van het bewustzijn - hij zal toen tien, twaalf jaar geweest zijn: een slaaf kende zijn leeftijd slechts ongeveer, door het verband met onthouden gebeurtenissen of eigen lotge-

1) staat $=$ plantage. 
vallen - bleef hem de herinnering bij van de tucht van zweep en bullepees en tamarinde-roede op de plantages, de straffe tucht tegen onwil en overtreding, och! niet eens altijd dáártegen: het werd zoo nauw niet genomen. Eerst veel later drong het tot hem door, dat geeselen en brandmerken nog voor slaven gehandhaafd bleef, toen de wet het voor alle anderen had verboden.

Het waren echter niet uitsluitend verhalen van wreedheid, ruw recht en onrecht, die hij beluisterde uit de monden der welbespraakte vertellers, er waren ook die opwekkende geschiedenissen, prettig om als tegenstelling aan te hooren, van slaven-listigheid en slaven-bedrog en slim bedacht verraad en die van de wegloopers, de onoverwinnelijken in de bosschen aan de andere zijde van de Cottica, waar zij, aan twee kanten bestookt, toch altijd wisten te ontkomen; hij vond ze kranig, de plunderaars van menige plantage, de vrouwen-roovers uit de wildernis. Hoe weinigen van de vervolgers, die langs de Matappica gevaren kwamen, waren teruggekeerd! Ergens tegenover Ephrata bleven de geraamten achter in den drassigen grond.

En dan waren er die graag opgesmukte overleveringen, haast als sproken, van lustige slavenfeesten, dagen lang dansen en overvloedig eten, uitbundige drinkgelagen en wild, losbandig zinnespel. Op den weg van mond tot mond waren de feesten uit vroeger tijd rijker en schitterender geworden, fantastischer aangekleed en bedriegelijk verfraaid, als had de ontbering van alle ontspanning in de geesten eene behoefte gewekt aan verblijding, - zij het met vreugden van weleer, - van het doffe leven van den slaven-dag.

Als timmerman en bootenmaker had Mentor's vader een milder bestaan op de plantage dan de slaven, die in het veld werkten en Mentor zelf, in zijns vaders vak, deelde in het voorrecht, dat hij niet met de ploegen den tuin in hoefde. Er was altijd wel wat te spijkeren en te krammen, te lappen en te breeuwen aan de woningenvan den directeuren van de opzichters, aan het magazijn en de loodsen, de sluizen, ponten, tentbooten en opgeboeide korjalen, die vloot 
der plantage. Maar soms, als haastig geplukt moest worden in den koffie-aanplant, - het was nog de tijd van de Surinaamsche koffie, wier bessen gelijktijdig rijpen, - of als er dijkbreuk was of er eens extra gewied moest worden, dan kreeg ook Mentor eene taak en onderging de harde heerschappij van den bastiaan, den neger-officier, zelf van slaven-bloede, doch des te straffer in zijne tucht, nu hij op zijn beurt overste over de zijnen was geworden. Nog iets anders leerde hij in het samenleven met de slaven. Het was het geknoei, het stelen van vruchten, het azen op voordeeltjes en voorrechtjes, het erbarmelijk gescharrel en gekonkel om iets te verwerven, wat méér te hebben dan de matige toebedeeling van recht en goed, de angst voor ontdekking van overtredingen, al waren zij nog zoo onbeduidend, het liegen om te verbergen uit vrees voor straf, het verheimelijken voor elkander, het bespieden van elkander uit zelfbescherming of om er bij te winnen: al dat bederf, dat, ontbrand in het broeiend kwaad der slavernij, doorbrandde in de geesten, geslacht op geslacht, daar geslacht na geslacht geplaatst werd in dezelfde levensomstandigheden, onder denzelfden druk, op hetzelfde levensvlak van nietswaardigheid.

In Mentor was eene sterkte van goedheid, die hem beschutte tegen de kracht van het kwaad. Hij was trouwens nog jong, toen de bevrijding aanbrak. Maar toch zette zich ook in hem ièts vast van den leugen en véél van de achterdocht.

In Mentor's jongelingsjaren werd de plantage geregeld bezocht door een zendeling van de Broedergemeente om de Blijde Boodschap ook tot de slaven te brengen. In vroeger tijd, toen zijn vader nog kind was, bestond een zendingspost op Sommelsdijk, die verlaten werd omdat hevige koortsen er de levens sloopten. Later werd een post gesticht op Anna's-zorg aan de Warappe en vandaar uit bezochten de Broeders de omliggende plantages, Esthersrust, Broedershoop, Herstelling, Frederikslust, Klein Lunenburg, Barbados, Badenstein, Kerkshoven.... zoo vélen, vélen, die destijds gerijd lagen aan de oevers van de kreken en kanalen in de buurt der samenvloeiïng van Cot- 
tica en Commewijne. Het kostte veel tijd, moeite en geduld om toegang te krijgen. De landheeren zagen ongaarne de zendelingen komen, want zij vreesden de verheldering, die zij brachten in de geesten der onderworpen slaven. Voor de slaven zelven was het eene wonderlijke gewaarwording, die de prediking van het Evangelie in hen wekte. $\mathrm{Zij}$, wier gansche bewustzijn doortrokken was van on-vrijheid, gehoorzaamheid-uit-dwang, volstrekte armoede, on-zekerheid en vrees en die het leven slechts kenden als tweeërlei beweging: het begeerenswaardige, onbereikbare leven der meesters, waarin maar enkele begunstigden eenigermate - maar o! zoo weinig! — mochten deelen en daartegenover, vèr ervan verwijderd, hun eigen nooddruftig leven, zij konden zoo moeielijk als waarheid aannemen de verkondiging van een geheel andere bedeeling, eene bedeeling van liefde voor allen, genade voor allen, van een Vader voor allen, dezelfde voor hen als voor hunne meesters, die zoo eindeloos bevoorrecht schenen boven hen. Zij konden het niet verwerken, dat in het Rijk van dien Vader allen gelijk waren, slaven en bastiaans en directeuren en dat Christus de Zaligmaker was, óók voor hen. En hoe onbegrijpelijk was die vergeving! Vergeving voor slaven, die alleen wisten van straf!

De zendelingen brachten hun dit alles, keer op keer, jaar in jaar uit, als onomstootelijke waarheid, en het wonderlijkste was wel, dat zij het uitsluitend deden om hunnentwil; het ongelooflijke, dat zij niets er voor vroegen van hen, geen dienst en geen offer, doch alléén maar gaven, met ernstige zachte woorden vertroosting aandroegen, bemoediging uitdeelden, medeleefden met hun nederig leven.

Het was genoeg om te aarzelen, genoeg om zich achterdochtig af te keeren. Maar in hun innerlijken nood grepen zij toch naar de onbegrijpelijke uitredding en velen hielden, eindelijk, vast wat zij langen tijd weifelend betast hadden. Mentor was een volwassen knaap toen hij gedoopt werd en van den zendeling wat onderwijs ontving in lezen. Schrijven mocht nog niet; de wet verbood het.

Ergens in het achterland van „De Overvloed” lagen 
Mentor's ouders begraven met zoovelen, wier rustplaatsen niet aangeduid waren door uiterlijke kenteekenen, - misschien had de zee, die er gestadig invrat, hen al weggespoeld, - toen de vrijverklaring een einde maakte aan de slavernij. Het saluut van den dag der bevrijding, dat de kanonnen van fort Zeelandia in den vroegen ochtend van den 1sten Juli van 1863 uitzonden over de wateren, drong niet door tot het afgelegen land van Cottica, maar toch vierden ook daar de verlosten luidruchtig feest langs de rivieren en kreken, tot in de Perica toe. HetZendingskerkje van Charlottenburg, met groen en bloemen en vlaggedoek getooid tot een loofhut, kon niet allen opnemen, die van heinde en ver in korjalen en visschersbooten aantogen om er te danken en te jubelen. Buiten stonden er, opeengepakt aan de open deuren en ramen van het propvolle kerkje, luisterend naar de blijde woorden van den leeraar op den kansel, medezingend de lofzangen uit het Negerengelsch liederenboek der Hernhutters.

In en om alle kerken van stad en land richtten dien avond duizenden zangers zuilen van zangen op, en de klanken vielen als vonken van vuurpijlen over het stille land, vervloeiden op de breede wateren en verstomden in de wouden.

In den nacht verlichtten de vuren op de plantages de feesten der bevrijden. Bij de loodsen op „De Overvloed” dansten zij een wilden dans op den opzweependen dreun van zware trommen, met hijgende borsten, schokkende lijven en vreemd geroep van mysterieuse woorden. Hoort! heftigerbeukt de trommelslager op het dof-dreunend klankbord, sneller en sneller; hij werpt den wilden kop omhoog, siddert mee met elken schok; harder, harder bonkt hij met zijne vuisten, totdat een verstillende rilling het lichaam verstart.... de oogen staren vaag weg.... en over het gelaat trekt de vreeselijke grijns van een wilde verrukking. Stil wordt het om hem heen; bewegingen en geluiden verzinken; wachtende, angstige, zoekende oogen houden hem vast; hij heft zijne armen: de geest, de winti, heeft hem gegrepen!

Verdwaasd richt hij zich op, loopt onzeker, waggelend 
als een beschonkene, zonder doel; hij valt, weer staat hij, strompelt, tastend in de ruimte en stamelt in zijn val, onverstaanbaar....

In den nacht, bij het licht der vuren, dansten de slaven den geheimzinnigen heiden-dans.

\section{III}

Met de vrijverklaring begon de uittocht.

Als zijne makkers sloot Marius het verplicht verband, dat de vroegere slaven nog tien jaren moest vasthouden aan de plantages. Maar zij wrokten over dien dwang, zij wilden niet blijven op de plaatsen, waar zij als slaaf gewerkt hadden en trokken uit naar andere plantages, de rivier af, stadwaarts.

„De Overvloed” verliep. Er bleven geen handen genoeg om het wied te weren, den oogst te bergen, de trenzen op te halen en de dammen aan te aarden. Van de zeezijde sijpelde het zoute water in de krabbengaten en boorde de gangen uit; vóór verspoelden de zware regens den kruin van den voorpolder en het brakwater drong binnen bij springtij en sleep een toegang uit voor elken vloed; de bodem verziltte in het laagland.

Marius trok mee. Op Reynsfort, het negerdorpje, genoot hij de luierende rust van ongedwongen vrijheid. Hij toog met de visschers naar de vischplantage Moed en Kommer en gooide er de netten uit in de vijvers en jaagde er snippen en doksen ${ }^{1}$ ) op de banken. Aan de zeekust verwijlde hij met hen in de strandhutten en als hij op de hassí, het modderpaard, over de slibruggen gleed en de visschen knuppelde, die bij val in de afzetnetten achterbleven, dan leek hem zijn leven zoo ruim en open als de wijde zee vóór hem en schalde zijn lach en schetterden zijn woorden uit boven het ruischen der vlakke golven. Zalig was het gedoken wachten bij de barbakotten ${ }^{2}$ ), waarop kwerimans en harders, geelbaggers en jonge haaien te rooken lagen boven zachtbrandend vuur.

\footnotetext{
1) doksen $=$ eenden.

2) barbakot = houten rooster voor het drogen en rooken van visch.
} 
Hij trok verder, medegesleurd door den stroom van trekkers, aangewakkerd door den innerlijken drang naar onbelemmerde toeëigening van de vrijheid, aangegrepen door de onrust, die de emancipatie in de harten der bevrijden had gewekt.

Hij dwaalde stroomafwaarts, de Commewijne zig-zag kruisend. In de Orelana-kreek toefde hij korten tijd op de verwilderde, verscholen gronden, waar levenszatte avonturiers en afstammelingen van vrijgegevenen een onbewogen leven sleten en vreemde, onbegrijpelijke namen Vide bouteille, Court d'argent - geheimenissen uit de historie der plantages vasthielden.

Op Zorg en Hoop was het eene vrouw; aan de overzijde, op Spieringshoek, arbeid, die zijn tocht onderbrak. En kruiselings vervolgde hij zijn weg, naar Killenstein en Leliëndaal, van Ellen naar Frederiksdorp, van Resolutie naar fort Nieuw-Amsterdam.

Daar was het leven als een spel, zoo druk van beweging, zoo vol van ongekende verrassingen. In den vroegen ochtend al, wanneer signalen klonken van het plein voor de kazerne, was het alsof een feestdag werd aangekondigd. Hoe boeide het exerceeren van den troep, het huiveringwekkend afschieten van de kanonnen, het wonderlijk seinen met kleurige vlaggen aan de seinpaal bij den uitkijk. In den breeden mond der rivier kwamen de groote zeilers aanvaren uit verre landen, zij ankerden voor den steiger en het was een onverzadigbaar genot gade te slaan wat daar gebeurde op het dek, het bezige geloop en winden van touwen. Heele vloten lagen er van tentbooten, korjalen en ponten, te wachten op gunstig water om op te stevenen naar de stad of de Commewijne in te varen. In den middag was het gezellig druk op den weg naar den waterkant van slenterende militairen en mooie meisjes in de fleurigste kotto-dracht.

Het was een heerlijk leven, maar Marius' verlangen trok als de begeerten van de meesten zijner lotgenooten naar Foto, de stad Paramaribo. Nog eenigen tijd hield Susanna'sdaal hem tegen, doch de tijdschoten die hij driemalen daags van uit destad dof hoorde naklinken op de plantage, 
wenkten hem onweerstaanbaar naar het beloofde land.

En hij stak de rivier over en doolde stadwaarts over Rainville en Combé....

Het was er armoe, in de begeerde stad. Pinarie! Hij dwaalde naar de bootwerven om werk - maar het bedrijf ging ten onder met de plantages; hij zocht een timmerbaas - maar er waren er velen te veel en zij konden geen knechten lijden. Somwijlen vond hij een karweitje, sjouwwerk aan den steiger, en andere dagen, als er niets te verdienen was, at hij mee van het armoed-potje van gauwgemaakte vrienden, eigenlijk arm als hij, maar toch altijd wel bereid iets af te staan aan elkander. En aan de markt viel wel eens een bacove af of schoot een spiertje gebakken maïs over of er was een zacht-gezind vriendinnetje, dat hem smullen liet uit de keuken van hare meesteres. Het ging nog - hoewel het feitelijk één bittere teleurstelling was.

Toch hield Marius zich groot en mengde zijn bluf in de opgesmukte verhalen van andere genooten, die aan de Platte Brug hun eigen misère wèg-betoogden met grootspraak. Zij hadden de stad gewild, hun hevigst verlangen was bevredigd: nu moesten luide stemmen het klagen in hun binnenste overschreeuwen, fantastische verzinsels verbergen de schrijnende waarheid van het verbijsterde ontwaken uit fantastische droomen. Zij deden zooals hunne vaders in den slaventijd gedaan hadden, die tot vorstelijke festijnen verfraaiden wat niet anders geweest was dan een glimpje van grof pleizier op hunne levensvlakte.

Foto was een groote teleurstelling!

En toch was die weer niet zoo heel moeilijk te verwerken. Marius was het echte negerkind, drager van een onverwoestbaar optimisme, een vlugge blijheid, wèl ree in het beklagen van zichzelven, gauw ontmoedigd onder tegenslag, maar toch ook dadelijk weer opgevroolijkt, uit den nood gewekt, wanneer maar even een straaltje van zonnige vreugde en hoop doorbrak, even een lichtje opflikkerde aan den horzion van het lastige leven. Hij vond blij vermaak in de beweeglijkheid aan den Waterkant, het komen en gaan der schepen - hier was het nog wat anders dan bij Nieuw-Amsterdam, veel échter, met dat lossen en 